\title{
Preface for the special issue of International Design and Concurrent Engineering Conference \& Manufacturing System Conference 2017 (iDECON/MS 2017)
}

The International Design and Concurrent Engineering Conference \& Manufacturing System Conference 2017 (iDECON/MS2017) was held in Osaka during September 7-8, 2017, the second time in Japan, co-hosted by the two divisions of Japan Society of Mechanical Engineers, namely, Design \& Systems Division and Manufacturing Systems Division. As a unique international conference hosted by the two countries, Japan and Malaysia, iDECON/MS offers a wonderful opportunity for researchers, practitioners, and students from both countries to get together, to know each other, to share ideas and to find an opportunity towards the potential academic partnership for future collaboration.

The program of iDECON/MS 2017 was organized as the following sessions: Reliability and Ergonomics in Design, Virtual Engineering and Concurrent Engineering, Rapid Prototyping and Reverse Engineering, Sustainable Materials, Design and Manufacturing, Lean and Flexible Manufacturing Systems, Production Management, Supply Chain Management and Global Manufacturing Management, Intelligent and Smart Mechatronics Systems, Intelligent and Smart Manufacturing Systems. The total number of participants reaches to 63, including Thailand and Indonesia, as well as the major participants from Japan and Malaysia.

It is our great honor to edit this special issue, entitled "Design and Concurrent Engineering Challenges for Sustainable Smart Manufacturing" in the Journal of Advanced Mechanical Design, Systems, and Manufacturing. For this special issue, Akira TSUMAYA (Kobe University) served as the chief editor, under the editorial team of Teruaki ITO (Tokushima University), Kazuo HIEKATA (University of Tokyo), Koji IWAMURA (Osaka Prefectural University), Hirohisa NARITA (Meijo University), Yutaka NOMAGUCHI (Osaka University), Masashi OKUBO (Doshishia University), Tsuyoshi KOGA (Yamaguchi University), Eiji MORINAGA (Osaka University), Masato INOUE (Meiji University), Toshitake TATENO (Meiji University), all of these served as the members of organizing committee of iDECON/MS 2017. The editorial team has screened candidate papers based on the review results on 51 accepted papers in iDECON/MS 2017, and reviewed again by the general review process of the journal to select the 8 papers for publication in this special issue. These papers cover advanced scientific topics in iDECON/MS 2017.

Finally we would like to express our sincere gratitude to the authors who have contributed their papers to this special issue, and the reviewers who worked very hard to complete their assignment on schedule for publication. The credit of this special issue goes to all of the participants of iDECON/MS 2017.

Nobuhiro SUGIMURA

Steering Committee Chair of iDECON/MS 2017 Graduate School of Humanities and Sustainable System Sciences Osaka Prefecture University, JAPAN 